\title{
Postmodernismo: ¿Una posibilidad de desarrollar propuestas creativas en artes visuales?
}

\author{
JAIME RUIZ SOLORZANO"
}

0 i bien hasta la década de los 60's se tenía más o menos claro a que escuela o tendencia artística pertenecían los distintos objetos bi o tridimensionales creados, hoy tales referentes son difusos, las lecturas son disímiles y la crítica, mediadora entre el creador, la obra y el público, se encuentra cargada de metáforas y giros del lenguaje incomprensibles para el grueso de la población; es decir, el arte cada vez se hace más críptico, aún para los mismos comprometidos en el circuito de creación - valoración - difusión consumo que asiste al arte.

En consecuencia, en nuestro medio, el estereotipo al cual se recurre con mucha frecuencia para dilucidar las creaciones visuales de las dos últimas décadas se fundamenta en el marco del postmodernismo, acatado sin la más mínima reflexión o posición crítica como si todo el mundo tuviese la certeza de lo que se explícita, acto propio de nuestra cultura simuladora.

Docente del Departamento de Artes de la Universidad Surcolombiana.

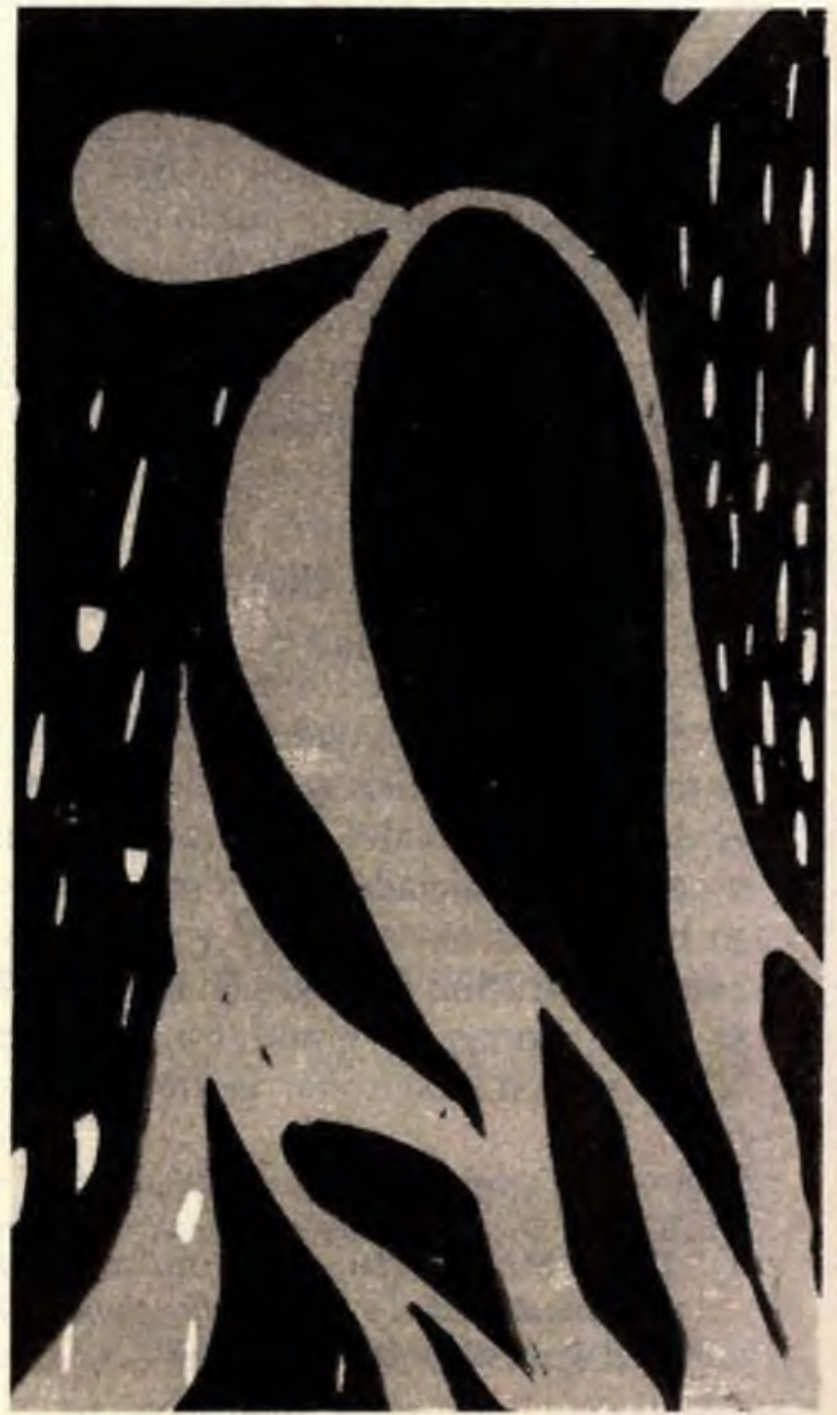

Ilustración: Rubén. 
UNIVERSIDAD SURCOLOMBIANA

Sin embargo, a unos cuantos nos asalta la sospecha al respecto, refractada en varios interrogantes: ¿Cuál es la noción de modernidad - postmodernidad que poseemos?, ¿Desde cuándo se habla de postmodernismo artístico?, ¿Qué es en sí el postmodernismo?, ¿De qué manera podemos caracterizar el postmodernismo artístico?, ¿Cuáles han sido las rupturas y fisuras que éste causó al modernismo?, ¿Es oportuno refuncionalizar el postmodernismo?, ¿Qué implicaciones de tipo ideológico conlleva?, ¿Bajo cuáles justificaciones?, ¿Significa el marco del postmodernismo una amplia posibilidad de desarrollar propuestas creativas en artes visuales?. Tales cuestionamientos ameritan aventurar una aproximación a sus respuestas, las cuales requieren de mayor concreción y profundización por lo cual son abordadas como una revisión y valoración de tesis ya elaboradas que pueden alumbrar y enriquecer el quehacer artístico, tanto de nuestra academia como de la vida profesional.

\section{Sobre la noción de modernidad - postmodernidad}

Por postmodernidad se comprende el momento de crisis o transición ante el descreimiento del paradigma de la modernidad, iniciado con el movimiento humanista del siglo XV y perfilado con la ilustración del siglo XVIII, al cual se le cuestionan sus grandes proyectos: "Consistía en desarrollar la ciencia ob- jetiva, la moralidad y las leyes universales, y el arte autónomo, de acuerdo con su lógica interna"'. Simultáneamente pretendía liberar a la humanidad de las ataduras opresoras; de igual manera con la especialización y el acumulamiento de la cultura se tendía a la organización racional y el enriquecimiento material de la vida cotidiana. Es decir, el uso de la razón terminaría por controlar la naturaleza, hacerla productiva, superar la escasez y prever las catástrofes. Mientras la racionalidad aplicada a la organización social y el pensamiento posibilitaba superar el uso arbitrario del poder e instaurar el sistema democrático, al mismo tiempo que liberaba al hombre de las supersticiones propias del mito y la religión ${ }^{2}$.

A pesar de sus grandes logros, el fracaso de tal paradigma se evidencia en la acumulación de capital y sobreabundancia de los países del centro y el empobrecimiento de la periferia, mientras que la industrialización y la sobreexplotación de los recursos naturales produjeron el desequilibrio ecológico planetario. Como consecuencia de las pugnas económicas y de la concentración del poder se suscitaron las dos guerras mundiales, los conflictos revolucionarios, la llamadas "guerras de baja intensidad", el imperialismo en sus distintas vertientes y la hegemonía de los Estados Unidos. Así el modelo de la modernidad propagado por la cultura accidental es tan sólo un enunciado incompleto e irrealizable, ante eviden-

1. HABERMAS,Jurgen. Modernidad versus posmodernidad en Debate Modernidad Postmodernidad y sus Implicaciones desde el punto de vista ético. Neiva, Ed. USCO CINDE, 1997, p. 24.

2. HARGREAVES, Andy. Profesorado, cultura y posmodernidad. Madrid, Ed. Morata S.L., 1996, p. 52. 
PAIDEIA

cias tan concretas como la marginalidad del tercer mundo.

En esta exabrupta conceptualización se considera desligitimizado el saber: "En la sociedad y la cultura contemporáneas, sociedad postindustrial, cultura postmoderna la cuestión del saber se plantea en otros términos. El gran relato ha perdido la credibilidad, sea cual sea el modo de unificación que se le haya asignado: relato especulativo, relato de emancipación"3. Desde este punto de vista las respuestas o los relatos dados al caos del mundo, donde la humanidad ha construido las grandes explicaciones sobre el universo, que se suponían omniabarcadoras y definitorias como las construcciones filosóficas de Kant, Hegel y Marx, entre otras, quedan en suspenso el ser señaladas de reduccionismos teóricos ante lo inconmensurable de la realidad; por lo cual el postmodernismo se puede definir también como "el fracaso consumado del reduccionismo, y surge justamente como consecuencia de ese fracaso" 4 .

En síntesis si la modernidad significaba la suma y la exaltación de la razón, la fe exagerada en la misma, su uso instrumental y el dominio de teo- rías y sistemas; la postmodernidad comprende la negación de la primera, denota la duda, crisis y muerte de la razón, como también el tiempo para el escepticismo y la praxis ${ }^{5}$.

Vale la pena recalcar que los términos modernidad, modernismo y modernización son similares pero de significación diversa. De tal manera autores como J. Habermas, M. Berman y N.G. Canclini proponen "la modernidad como una etapa histórica, la modernización como proceso socioeconómico que trata de ir construyendo la modernidad, y los modernismos, o sea los proyectos culturales que renuevan las prácticas simbólicas con un sentido experimental y crítico" 6 . Para el fin que nos interesa A. Hargreaves define el modernismo como la "forma intelectual, estética y cultural o el movimiento mediante el cual se expresa o se presenta esa forma"7.

Analógicamente cuando se habla de postmodernidad se entiende "una condición social. Comprende determinadas pautas de relaciones sociales, económicas, políticas y culturales. Se caracteriza por el abandono de los ideales de la ilustración europea, el escepticismo respecto a las nociones tradicionales de

3. LYOTARD, Jean - Francois. La condición postmoderna. Madrid, Ed. Cátedra, p. 73.

4. FRIDMAN, Pablo. Un debate que se dá de hecho: Psicoanálisis Vs. Postmodernismo. Texto Internet, 1988, p. 1.

5. RUBIO, Miguel El contexto de la modernidad y la postmodernidad en Debate Modernidad - Postmodernidad y sus Implicaciones desde el Punto de Vista Etico. Neiva, Ed. USCO CINDE, 1997 p. 138.

6. GARCIA CANCLINI, Nestor. Culturas hibridas estrategia para salir y entrar de la modernidad. México, Ed. Grijalbo, S. A. 1990, p.19.

7. HARGREAVES, Andy. Op. Cit. P.51. 
razón, verdad, identidad, objetividad, Ilustración: Diana Yamile Olarte subjetividad; la incredulidad y desconfianza respecto a los ideales de emancipación o progreso y la afirmación del fin de la historia, del sujeto, de las explicaciones absolutas, de los metarelatos; y la exaltación de la diferencia, la "otredad", la diversidad, la singularidad, la contingencia, la relatividad, la multisignificación. Desde este punto de vista, el postmodernismo es un aspecto del fenómeno más general de la postmodernidad. Es un componente y consecuencia de la condición social postmoderna. En muchos sentidos es un efecto de la postmodernidad"8.

\section{Ubicación cronológica, concepto y caracterización del post-modernismo artístico}

En lo que respecta al arte se

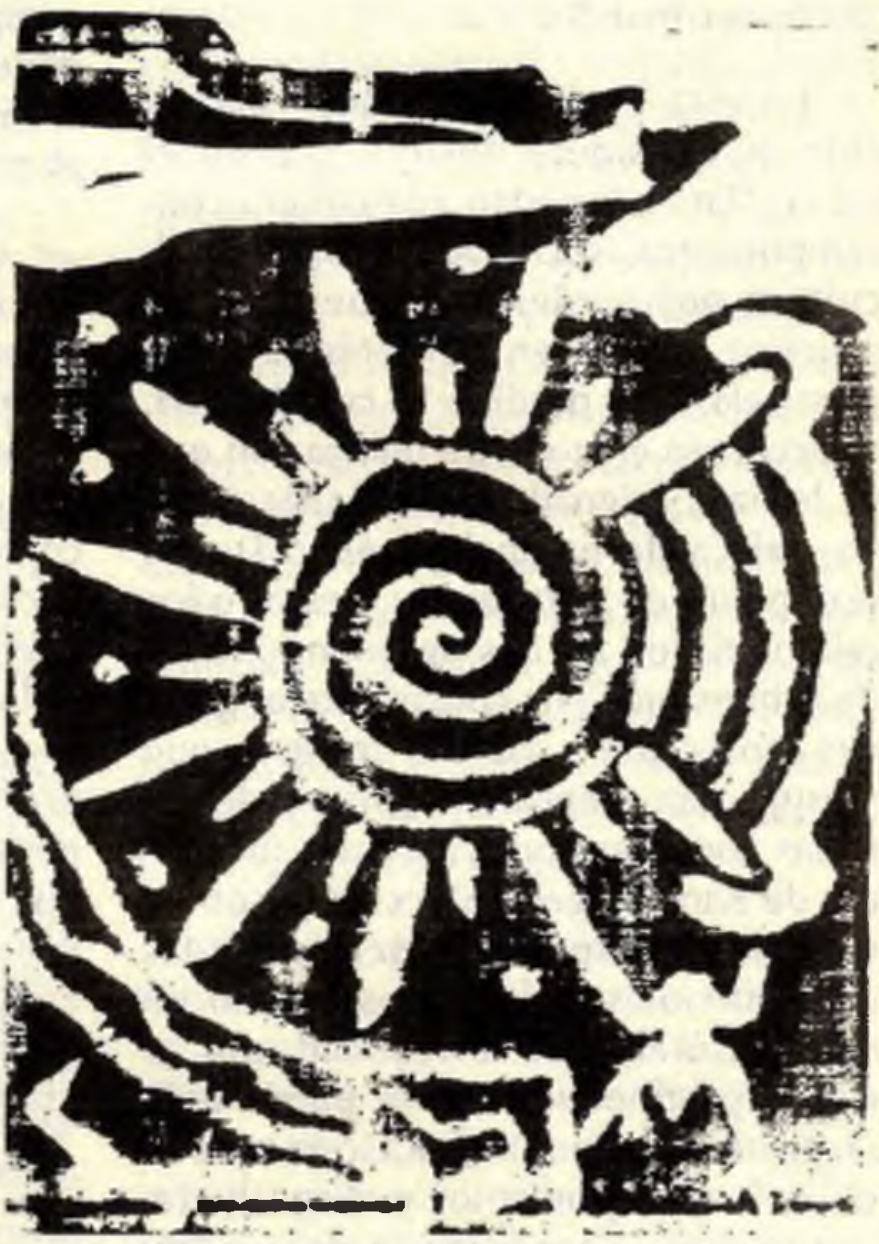
comienza a hablar de postmodernidad en la década de los sesenta como "envejecimiento" de la modernidad estética, por ello dice J. Habermas: “Octavio Paz ... notó ya a mediados de los sesenta que la vanguardia de 1967 repite los actos y ademanes de 1917 . Estamos experimentando el fin de la idea del arte moderno"9. Otros como J. Acha consideran que el postmodernismo artístico se inicia como práctica en la década de los cincuenta con los

environments (ambientaciones) y en los happenings (acontecimientos) de 1958, los cuales se pueden remitir al arte Dadá (1914-1922); pero que a partir de los sesenta inician su apogeo. El denominador común de estas manifestaciones creativas se basa en la ruptura de los procesos técnicos tradicionales, la mezcla de distintos lenguajes artísticos, la comunicación activa y la participación directa del espectador. ${ }^{10}$

8. Ibidem. P. 65.

9. HABERMAS, Jurgen. Op. Cit. P. 20.

10. ACHA Juan. Arte y Sociedad en America Latina. México, Ed. Fondo de Cultura Económica, 1981, p. 138. 
Paddela

Dentro del ámbito nacional $\mathrm{L}$. Estrada afirma que el postmodernismo "se emplea en arquitectura desde 1975 "11. En nuestro país se institucionaliza con el XXXV Salón Nacional de Artistas Colombianos desde 1994.

Las definiciones de postmodernidad son varias. Para J. F. Lyotard "sería aquello que alega lo impresentable en lo moderno y en la presentación misma: aquello que se niega a la consolación de las formas bellas, al consenso que permitiría presentar en común la nostalgia del imposible; aquello que indaga por presentaciones nuevas, no para gozar de ellas sino para hacer sentir mejor que hay algo que es impresentable"12.

Lo impresentable lo plantea el pensador retomando lo que Kant llamó el juicio reflexivo, o sea, "la capacidad de concebir y la capacidad de representar un objeto correspondiente al concepto" para definir lo presentable. En consecuencia, lo impresentable es la incapacidad de presentar, hacer ver, un concepto con un objeto; dentro de estos conceptos impresentables se encuentran "las ideas de mundo (la totalidad de lo que es)... la idea de lo simple (lo no descomponible)... lo absolutamente grande, lo absolutamente poderoso... lo infinito". Según J.F. Lyotard, aquí reside, en la presentación de impresen- tables o contenidos ausentes, el campo de desarrollo de la pintura moderna; la cual conlleva la descalificación y abandono de la realidad ${ }^{13}$.

De manera más concreta el postmodernismo "es un fenómeno estético, cultural e intelectual que abarca un conjunto concreto de prácticas y formas culturales en las artes plásticas, la literatura, la música, la arquitectura, la filosofía y el discurso intelectual en general" 14 .

Al respecto J. Acha dice:" por postmodernismo entendemos el conjunto de contrahumanismos que actúan en la producción cultural, si es que identificamos con el Renacimiento y con su estética eso de que el hombre -casi siempre el ideal o postulado abstracto- "es la medida de todas las cosas" y aquellas ideas de espacio y tiempo, arte y realidad que van adheridas a la fetichización del objeto o a los idealismos subjetivistas, hoy periclitados"15.

Específicamente en lo que concierne al arte L. Estrada explica que el postmodernismo es una "denominación pluralística y un poco vaga... se refiere a una convergencia de estilos. Cubre seis tendencias que parten del modernismo: el historicismo, lo neovernáculo, el edoccismo, el contextua-

11. ESTRADA., Leonel. Diccionario de arte actual. Medellín Ed. Colina, 1985, p. 201.

12. LYOTARD, Jean - Francois. Respuesta a la pregunta: ¿Qué es lo postmoderno? en Debate Modernidad - Postmodernidad y sus Implicaciones desde el Punto de Vista Etico. Neiva. Ed. USCo-CINDE,1997, p, 39.

13. Ibidem

14. HARGREAVES. Andy. Op. Cit. P. 64.

15. ACHA.juan. Op. Cit. P. 139-140. 
lismo, la ideología metafísica y lo que concierne al espacio ambiguo"16.

No obstante, las anteriores explicaciones sobre el concepto de postmodernidad quedan incompletas si no lo caracterizamos debidamente dentro del devenir artístico. En efecto el postmodenismo va más allá del "pastiche, collage, deconstrucción, falta de linealidad, mezcla de períodos y estilos...", ya que la nueva actitud artística desborda los limites de los movimientos y vanguardias registradas por la historia durante el siglo actual.

Si bien J. Acha ha clasificado las distintas tendencias del postmodernismo de la siguiente manera: "A. Conceptos o arte conceptual (1965): arte - lenguaje, arte de procesos, arte informático y ready - made (1917). B. Espacios y materiales: ambientaciones (1958), arte pobre (1967), arte térreo (1967),y arte de sistemas (1971). C. acciones corporales. Eventos (1958) actuaciones(1954) y arte corporal (1961). D. Imágenes lumínicas y electrónicas (1963): proyecciones múltiples, cine artístico - visual y vídeo"17; hoy no son extrañas las "hibridaciones" de las tendencias anteriores dentro de un entrecruzamiento que destroza cualquier demarcación de los territorios expresivos.

No en vano afirma G. Zalamea: "en esta postmodernidad todas las tendencias conviven en un plano igualitario, cada pieza de este enorme mapa funciona libremente, afirmando su personalidad y enteramente despreocupado dé encajar en el conjunto" 18 .

Tal vez la caracterización más sintética que proponemos sea que el arte postmoderno es multidimensional y multideoestético, el cual pretende involucrar todos los sistemas perceptivos y trazar retos a la sensibilidad y la capacidad de comprensión - comunicación de la humanidad en este tiempo de extrañamiento y crisis finisicular.

De manera amplia el anterior autor considera que en el arte postmodernista "todo puede ser revisado, utilizado, reconsiderado, recuperado colocado en un nuevo contexto. Lo popular, lo local, lo raizal, lo falso, lo religioso, lo íntimo -entre decenas categorías posibles- entran por derecho propio en la historia del arte y los artistas se apropian sin ninguna inhibición de todas las ideas y materiales posibles" 19 .

3. Puntos de fisura y de ruptura con el arte moderno

Como quedó anotado inicialmente, el proyecto de la ilustración pensaba desarrollar un "arte autónomo, de acuerdo con su lógica interna", en sí vino a recoger las condiciones del creador genial evidenciadas por Marsilio Ficino, cuyos modelos son los artistas más importantes del Renacimiento; de

16. ESTRADA, Leonel. Op. Cit. P. 201.

17. Ibidem.

18. ZALAMEA, Gustavo. Introducción en Catálogo XXXV Salón Nacional de Artistas. Santafé de Bogotá. Ed. Litográfica Arco, 1994.

19. Ibidem. 
PAIDEIA

esta manera a mediados del siglo XIX el artista con talento podía dar expresión auténtica a aquellos motivos y experiencias "que tenía al encontrar su propia subjetividad descentrada, desvinculado de las obligaciones del conocimiento rutinario y la acción cotidiana"20.

Razones por las cuales el arte producido por las vanguardias del arte moderno durante el presente siglo devienen en dos grandes líneas. La primera, icónica sustentada aún en la representación mimética o la correspondencia representativa entre la realidad y la obra, esta línea termina relativizando la semejanza, el ilusionismo natural y las deformaciones expresivas; la segunda, anicónica deconstruyó el código icónico, lo redujo a unidades elementales y su organización sintáctica para encontrar el lenguaje propio del arte. F. Menna escribe que es "una confirmación de la certeza del diagnóstico propuesto por Kandinsky a propósito de la doble vía emprendida por el arte moderno, es decir, la vía de la gran abstracción y del gran realismo"21. De estas líneas se pueden dar ejemplos.

La primera línea se inicia con el Neoimpresionismo de Seurat cuyo color es la realidad, los collages cubistas (pintura - objeto) de Picasso y Braque, los cuadros blancos y negros del Suprematismo de Malevitch, el ready made (objetos prefabricados) del dadaísta Duchamp, los objet trouve (objetos encontrados) de los surrealistas, las paradojas lingüísticas ( jue- gos palabras - imagen) de Magritte, los objetos del Pop Art, las reproducciones humanas de los Hiperrealistas Hanson y de Andrea, que terminan negando la representación mimética de la realidad pues jamás lograron igualarla. Dentro de la segunda línea corresponde el Fauvismo de Matisse, el arte abstracto de Kandinsky, el rayonismo de Larinov, el neoplasticismo de Mondrian, el expresionismo abstracto de Pollock, la abstracción lírica de Wols y el arte óptico de Vasarely, los cuales crearon a partir de la interacción sintáctica.

No se hace alusión a las variantes expresionistas por ser derivados de la primera línea que de una $u$ otra forma tiene como referente lo reconocible.

Sintetizados de la anterior manera los procesos del arte moderno, la paradójico es que varios seudo artistas continúen hoy representando la realidad recurriendo al enfoque monocular propio de la perspectiva, la competencia artesanal y la pericia basada en normas y cánones impuestos desde el Renacimiento y avalados por los salones y academias de los siglos XVII y XVIII, cuyos modelos fueron ampliamente superados por la permanente búsqueda técnico-expresiva a partir del impresionismo; este modo de representar finalmente recibió el "tiro de gracia" con el empleo de la fotografía y el cine que plasman con mayor eficiencia y capacidad de difusión la captación de imágenes y movimientos de la realidad; quedando diluido así el oficio tradicional del artista.

20. HABERMAS. Jurgen. Op. Cit. P.25.

21. MENNA, Filiberto. La opción analítica en el arte moderno. Barcelona Ed. Gustavo Gili S.A., 1977 p. 53. 
Este anacronismo recalcitrante de pintores, escultores y algunos teóricos se debe, posiblemente, a la falta de modificar las estructuras mentales como consecuencia de ignorar la historia y la teoría del arte, a lo cual se suma el mercado de pinturas y esculturas artesanales exigido por el público "analfabeto Visual" que no ha tenido las oportunidades de desarrollar las capacidades senso-perceptuales y sensitivas.

Retomando lo escrito en la caracterización del postmodernismo, este hace grandes fisuras en las líneas icónica y anicónica al desbordar las tendencias inscritas en el desarrollo del arte moderno, ya que sus propuestas radicalizan y rompen con lo establecido al crear los no-objetualismos y las especificidades anti-formalistas. En consecuencia, el objeto representado y sus cualidades matérico-formales es desechado y negado porque los no-objetualismos cuestionan, alteran y transforman los fundamentos del arte moderno occidental, como prueba el arte del postmodernismo fusiona los límites de la escultura, la pintura y el espacio real, dejando sus justificaciones teóricas subvertidas. Ante lo cual afirma J. Acha: "estamos al fin y al cabo, ante manifestaciones que dan prioridad a conceptos y acciones, así como a efectos ambientales y perceptuales de unas imágenes lumínicas y electrónicas y de unos objetos efímeros y heteroclíticos que hacen las veces de mero soporte"22.

Por su parte el empleo del espacio, tiempo, materiales, movimientos, color, objetos y luz concretos, de verdad, cuestionan los procesos del conoci- miento, ponen en duda las relaciones de la percepción con el lenguaje y desafian provocadoramente el comportamiento de artistas y espectadores de manera sincrética.

De otra parte produce fisuras a los intereses comerciales y a la consagración oficial por ser obras efímeras, de "mal gusto" o con soportes y concreciones que no se pueden coleccionar, ni someter a las reglas del mercado, también difícilmente funcionan como aval de las élites y de ciertos sistemas.

En este sentido algunos autores consideran que el postmodernismo significa "el triunfo del populismo estético o desvanecimiento en ellos de la antigua frontera (esencialmente modernista)entre la cultura de élite y la llamada cultura comercial o de masas, y la emergencia de obras de nuevo cuño imbuídas de las formas, categorías y contenidos de esa "industria de la cultura" tan apasionadamente denunciada por todos los ideólogos de lo moderno desde Leavis y la "nueva critica americana" hasta Adorno y la Escuela de Francfort. En efecto lo que fascina a los postmodernismos es precisamente este paisaje "degradado, feista, Kitsch, de series televisivas y cultura de Reader's Digest, de la publicidad y los moteles, del "último pase" y de las películas de Hollywood de serie B, con sus categorías de lo gótico y románico en clave de folleto turístico de aeropuerto, de la biografía popular, la novela negra, fantástica o de ficción científica: materiales que ya no se limitan a "criticar" simplemente, como habrían hecho Joyce o Mahler, sino que incorporan a su propia esencia ${ }^{23}$.

22. ACHA, Juan. Op. Cit. P. 138.

23. JAMENSON, Federic. El postmodernismo o la lógica cultural del capitalismo avanzado. Barcelona. Ed. Paidos, 1991,p.12-13. 
PAIDELA

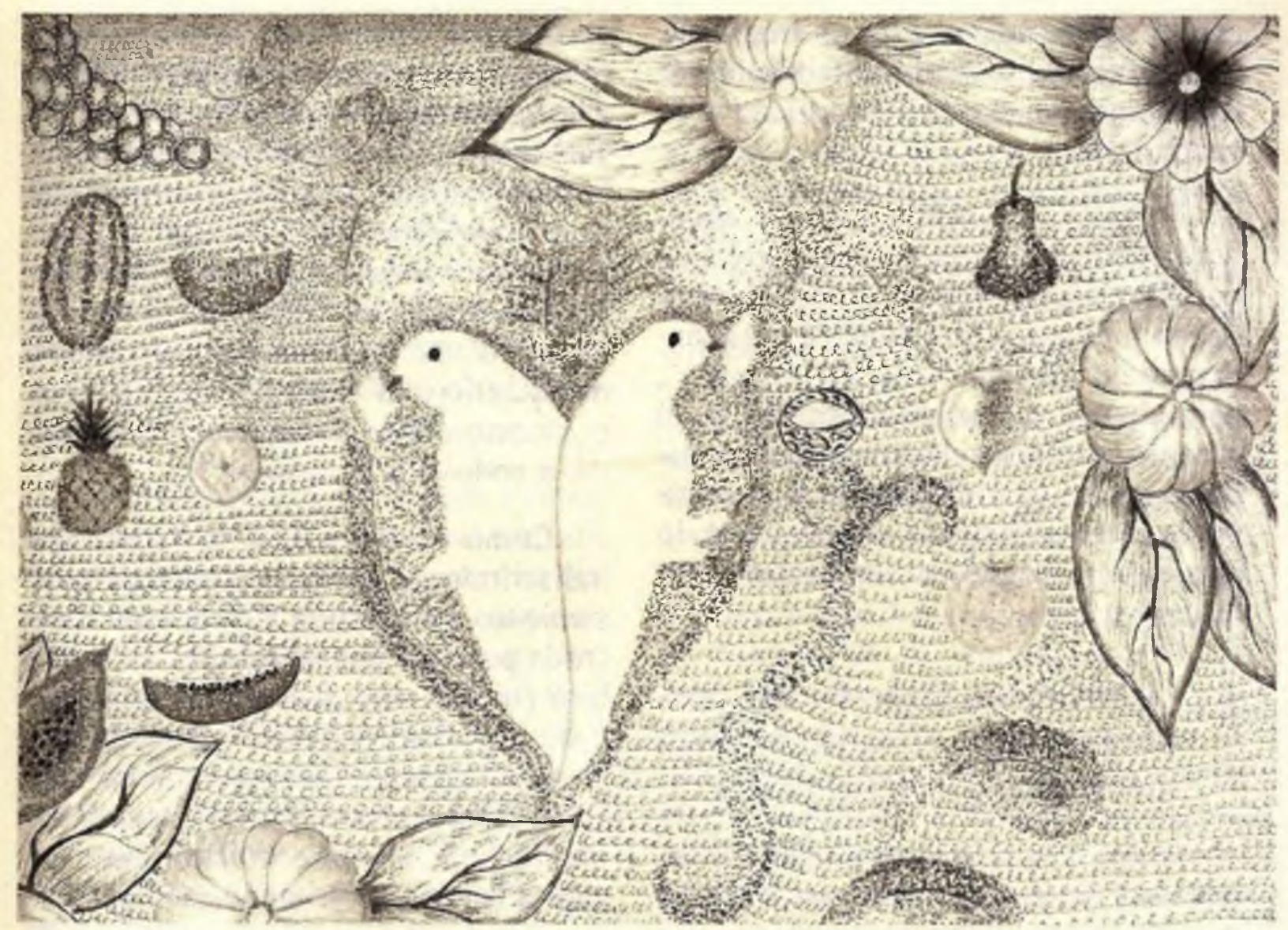

Dentro de las rupturas producidas al arte moderno, el postmodernismo niega los procesos lineales de causaefecto por imponer la simultaneidad de su componentes, lo cual tiene cinco consecuencias: Primera, implementa el concepto de aleación donde el todo como resultado es imprevisible en relación a las distintas partes que lo componen, teniendo su propia valoración cada una o en conjunto. Segunda, determina una ruptura definitiva con la narración y las obras grandilocuentes o con fines propagandistas. Tercera, considera el tiempo y el espacio como realidades circulares y polifocales. Cuarta, la antinarración conduce a que las obras sean abiertas sobre las cuales se pueden hacer múltiples lecturas; con ella los signos y significantes ya no remiten a un solo significado sino a otros signos por lo cual las obras son multisignificativas. Quinta, el uso de varios elementos simultáneamente produce nuevas formas de percibir y explicar la realidad, no se trata ya de interpretar el mundo y de ubicarse en él, sino definirlo y proponer que se debe hacer con el mismo; en sí, se abandona la idea de localizar la tarea del conocer por el intento de centrar al propio creador.

De esta manera podemos comprender las diferencias establecidas por Davis Harvey, citado por Erwin Silva, "en tanto el modernismo es romántico, el posmodernismo es dadaista. Mientras uno es jerárquico el otro es anárquico y si en el primero predomina la metáfora en el segundo domina la metonimia ... se establece que en la modernidad prevalece lo genital y lo fálico, la posmodernidad se diferencia 
por el poliformismo y la androginia... Harvey ve la posmodernidad como la fragmentación, la discontinuidad y lo caótico"24.

El postmodernismo además abandona los paradigmas artísticos creados por el antropocentrismo euronorteamericano moderno, "del hombre noratlántico como medida de todas las cosas", para abarcar la realidad amplia, plural y concreta y sus relaciones tiempo-espacio-seres, lo individual y lo colectivo, la interioridad y la exterioridad, lo particular y lo general, lo contextual y lo universal.

4. La refuncionalización del posmodernismo: Implicaciones ideológicas y justificaciones

Frente a la postmodernidad y el inmanente postmodernismo se levantan diversas posturas, ya sea recusándolos o bien armando constructos apologéticos. Autores como J. Jamenson señalan que "todo esta cultura posmoderna, que podríamos llamar estadoinense, es la expresión interna y superestructural de toda una nueva ola de dominación militar y económica norteamericana de dimensiones mundiales" 25 . Se señala críticamente que el postmodernismo contribuye a invalidar los fundamentos racionales, culturales, ideológicos y morales, entre otros, correspondiente a la "generalización de la decadencia" 26 . También "esto contribuye el preámbulo para justificar el vegetarianismo que se pretende inculcar a las nuevas generaciones, a esos niños que Lyotard les explica la postmodernidad, pensando en el futuro - presente del mundo noratlántico. El culto por lo "light" es el principio que fundamenta la renuncia a todos los principios"27.

Como resumen ante la aceptación indiscriminada de la corriente de pensamiento en cuestión F. Jamenson dice: "toda posición posmodernista en el ámbito cultural - ya se trate de apologías o de estigmatizaciones - es también y al mismo tiempo, necesariamente, una toma de postura implícita o explícitamente política sobre la naturaleza del capitalismo multinacional actual" 28 .

Es factible considerar ante un fenómeno tan crucial que no puede verse sólo en blanco y negro, sin analizar previamente sus tonos intermedios. Para ello es básico recordar que querámoslo o no estamos instalados en la postmodernidad. Así sea esta bien particular, por lo cual "se pueda afirmar que América Latina está participando de hecho de la postmodernidad" y de esa

24. SILVA, Erwin. Etica, p ostmodernidad y globalizacion. Texto Internet, 03/19/96. Pag 1,2

25. JAMENSON, Federic. OP Cit. p. 18-19.

26. BELL, Daniel. Las contradiciones culturales del capitalismo. Madrid, Ed. Alianza,1992, p.54.

27. GUADARRAMA GARCIA, Pablo. América Latina: iRescate postmodernista o rescate de la postmodernidad? en Revista Universidad del Tolima. Humanidad y Ciencias Sociales. Ibagué Ed.U. Tolima, 1994, p.92.

28. JAMENSON, Frederic. Op. Cit. 14. 
"condición posmoderna". Ella no es (nunca lo ha sido) ajena a ese proceso de transnacionalización económica e ideológica del capital; "nos concierne fatalmente -dice F. Retamar-aunque desde el lado de la sombra" 29 . En lo que concierne, constituiría un desacierto ignorar los procesos históricos culturales consuetudinarios de dependencia por los cuales Latinoamérica ha atravesado.

Sin embargo, no podemos aceptar que la dependencia estructural tan solo ha determinado repetir sin más lo que en otros lugares se produce, también se han elaborado importantes aportes a la cultura universal, bien sea naturalizándolos y replanteándolos, o bien generando propuestas nuevas como en los campos de la literatura y las artes visuales; sin olvidar que en los diversos contextos confluyen rasgos culturales premodernos, modernos y posmodernos, caracterizando de este modo la condición de "hibridez" latinoamericana.

Al respecto afirma N.G: Canclini: "Es sabido cuantas obras de arte y la literatura latinoamericana, valoradas como interpretaciones paradigmáticas de nuestra identidad, se realizaron fuera del continente, o al menos en los países natales de los autores... El lugar de donde escriben, pintan o componen música varios miles de artistas latinoamericanos ya no es la ciudad donde anudaron su infancia, ni tampoco esta en la que viven desde hace unos años, sino un lugar hibrido, en el que se cruzan los sitios realmente vividos... Pero esos pueblos, aunque se parezcan a otros tradicionales de Uruguay, Colombia y la Argentina están rediseñados por patrones cognoscitivos y estéticos adquiribles en Madrid, México o París"30.

A lo anterior se debe aunar que el discurso postmoderno propone: "El saber postmoderno no es solamente el instrumento de los poderes. Hace más útil nuestra sensibilidad ente las diferencias, y fortalece nuestra capacidad de soportar lo inconmensurable" ${ }^{31}$; en otras palabras es la posibilidad de articular la tolerancia, lo heterogéneo, el disenso, la diferencia frente a la misma edad imperante, a los paradigmas ya dados. Es decir, "el discurso posmoderno, en tanto proporciona variables atractivas por re-pensar las cosas desde la "otredad" (esa que siempre nos ha identificado), debe ser interceptado allí en lo que es asimilable y en lo que es provechoso" 32 .

Este desmontaje o desconstrucción del postmodernismo propuesto como refuncionalización se entiende también como el montaje o la reconstrucción de un nuevo "tipo de discursividad teórico- crítico de lo diacrónico y lo sincrónico del saber"... esta "nueva" discursividad o instrumento técnico tiene un

29. REVELO, Paul. Once tesis sobre modernidad postmodernidad en América Latina, en revista Universidad del Tolima. Humanidades y Ciencias Sociales. Ibagué. Ed. U. Tolima, 1994, p.107.

30. GARCIA CANCLINI, Nestor. Op. Cit. P. 306.

31. LYOTARD, Jean - François. La condición postmoderna Op. Cit. P. 11.

32. REVELO, Paul. Op. Cit. P. 109. 
denominador común, y es que se presenta como discurso desde lo "latinoamericano" (sin denominar a lo foráneo); se reconoce como plural, abierto, desprejuiciado, comprometido, desde lo alterativo y en pie de igualdad al mismo tiempo; que se autovalora como diferente." ${ }^{33}$; o como bien lo define Lyotard "el principio del movimiento que anima al pueblo no es el saber de su autolegitimación, sino la libertad de su autofundación o, si se prefiere, en su autogestión. El sujeto concreto, o supuestamente concreto, su epopeya es la de su emancipación con respecto a lo que le impide regirse por sí mismo"34.

Esta perspectiva se hace visible en la medida que se asuman las culturas como medio y resultado de la interacción social, ya que las estructuras sociales son, al mismo tiempo, "potentes (como marco de la acción) y precarias (vulnerables al cambio a través de esa acción)"35. Pero, sobre todo, en la medida en que superemos el "estado de melancolía", de la derrota decretada, de negar "las soluciones únicas" y ubiquemos "el presente en situación crítica", ${ }^{36}$; para el caso, el presente y su potencial creativo-expresivo como centro de preocupación, acción y reflexión, o en "proyectar, imaginar lo que vamos hacer"37.
5. Postmodernismo:

Posibilidad de desarrollar propuestas creativas en las artes visuales.

Tal y como hemos venido analizando la condición postmoderna entraña al tiempo el fin de las certezas, las ideologías, las clases sociales, los grandes relatos y los paradigmas artísticos impuestos desde las culturas hegémonicas y la oportunidad de refuncionalizar nuestra posición alterativa desde la periferia cultural.

Consecuentemente en el arte son aceptadas las rupturas y fisuras que el postmodernismo viene implementando sobre el desarrollo técnico, estético, significativo e ideológico del arte moderno y de las distintas reacciones que hoy se debaten en el campo de fuerzas y escenarios en el que han de direccionarse impulsos creativos diferentes llamados por Juan Acha y Raymon Williams "emergentes" ${ }^{\prime 3}$, haciéndose manifiestos en la actual producción cultural.

Esta situación ha llevado N.G. Canclini a preguntarse: " $i E n$ que reside, entonces, la novedad de la descolección, desterritorialización y la hibridez postmodernos?. En que las prácti-

33. Ibidem. P. 113.

34. LYOTARD, Jean - Francois. Op. Cit. P. 68.

35. HARGREAVES, Andy. Op. Cit. P. 68-69.

36. FONTANA, Josep. La Historia después del fin de la historia. Barcelona. Ed. Crítica, 1992, p.143.

37. MARQUINEZ ARGOTE, Germán. De la repetición a la investigación en ¿Qué es eso de la filosofia latinoamericana?. Bogotá, Ed. El Buho, 1986, p.147.

38. ACHA, Juan. Introducción a la creatividad artística. México, Ed. Trillas, 1992, p. 112. 
cas artísticas carecen ahora de paradigmas consistentes. Los artistas y escritores modernos innovaban, alteraban los modelos o los sustituían por otros...Pero creían había caminos, paradigmas de modernidad tan respetables como para merecer que se los discutiera. La visualidad postmoderna en cambio es la escenificación de una doble pérdida: el libreto y el autor... quiere decir que ya no existen los grandes relatos que ordenaban y jerarquizaban los períodos del patrimonio, la vegetación de obras cultas y populares en las que las sociedades se reconocian y consagraban sus virtudes" 39 .

La anterior explicación de N.G. Canclini hace alusión a una de las dimensiones postmodernas definida como el declive de las certezas, debido a la expansión de la información, del conocimiento y los intercambios multiculturales a nivel global, recurriendo a los múltiples canales de comunicación y la tecnología electrónica como principales medios. Por ello "el postmodernismo no es un estilo sino la copresencia tumultosa de todos, el lugar donde los capítulos de la historia del arte y del folclor se cruzan entre sí y con las nuevas tecnologías culturales" 40 .

Es más, este entrecruzamiento se encuentra nexado y pone en evidencia la búsqueda de la identidad cultural tratando de encontrar sus significados con contextos más locales, y como efecto también de otra dimensión postmo- derna inherente a la globalización económica y cultural del orden internacional imperante, al respecto dice $A$. Hargreaves: "A medida que se intensifica la globalización, cuando Mc Donald' s abre en Moscú, los sushi bars prosperan en New York y los paisajes urbanos internacionales se parecen más en la mercantilización global de la vida de las comunidades, asistimos al resurgimiento de las identidades étnicas, religiosas y linguiísticas de carácter más local. Las identidades nacionales, puestas en peligro por la globalización económica, se están reconstruyendo frenéticamente"41.

En esta nueva "poética" del reconocimiento se extrema la experimentación, las soluciones formales, la cotidianidad, la riqueza interior, las vivencias y relaciones con el exterior, los intereses comunicativos, las aventuras sensoriales y sensitivas.

Desde otro punto de vista, la historia del arte moderno ejemplifica la subjetividad de los creadores. Por ello "hoy pensamos que la exaltación narcisista del pintor o el cineasta que quieren hacer de su gestualidad el acto fundador del mundo es la parodia seudolaica de Dios. No le creemos al artista que quiere eregirse en gramático ilustre, dispuesto a legislar la nueva sintáxis"42. Estos enunciados identifican una tercera dimensión postmoderna que replantea el yo ilimitado. Ante lo cual el arte latinoamericano marca derroteros diferentes.

39. GARCIA CANCLINI, Nestor. Op. Cit. P. 307.

40. Ibidem.

41. HARVEGREAVES, Andy. Op. Cit. P.81.

42. GARCIA CANCLINI, Nestor. Op. Cit. P. 307-308. 
En esta dirección la subjetividad se amplía en el quehacer dialógico, vivo, flexible e interpretativo con contextos ampliamente motivantes y enriquecedores; mejor sustentado por N.G. Canclini cuando dice: "no veo en esos pintores, escultores y artistas gráficos la voluntad teleológica de inventar o imponer un sentido al mundo. Pero tampoco hay en ellos el nihilismo abismado... su crítica al genio artístico, y en algunos al subjetivismo elitista, no les impide advertir que están surgiendo otras formas de subjetividad a cargo de nuevos actores sociales (o no tan nuevos), que ya no son exclusivamente blancos, occidentales y varones. Despojados de cualquier ilusión totalizadora o mesiánica, estos artistas mantienen una tensa relación interrogativa con sociedades, o fragmentos de ellas, donde creen ver movimientos socioculturales vivos y utopías practicables”43.

Frente a la creatividad artística comúnmente se cree que los potenciales creadores no requieren participar en procesos educativos o re-educativos; lo cual es un error enorme ya que la "inspiración" artística, el "hacer silvestre" apoyado por algunos tecnócratas y seudo artistas decadentes y empíricos, de por sí no es suficiente, requiere del desarrollo de la maestría manual, de experiencias sensoriales y sensitivas, además de conocimientos históricos y conceptuales de las diferentes disciplinas y ciencias que han abordado el arte. Se debe aclarar que si bien el desarrollo de las anteriores no determinan de por sí la creación, sí la facilitan cuando se efectúa una debida apropiación.

- Está comprobado que a través de procesos educativos pertinentes al desarrollo de la pericia manual y de obtener experiencias sensitivas y sensoriales permiten la ejecución o materialización de obras; mientras el adquirir conocimientos históricos y conceptuales actualizados posibilitan la elección de los distintos géneros expresivos (pintura, dibujo, escultura, fotografía, diseño gráfico, cerámica, video - arte, expresión multidimensional, etc.) y las tendencias con las cuales se pueden articular los lenguajes creativos personales.

De aquí que es importante comprender el arte actual con sus distintos lenguajes, técnicas, tendencias y sus respectivos soportes teóricos para generar un arte orientado al ahora y al futuro. Es decir, la educación debe impulsar un arte emergente (innovador) y en el peor de los casos dominante (vigente); pero nunca residual (cadu$\mathrm{co})^{44}$.

Precisamente es aquí donde podemos avizorar las enormes posibilidades que nos ofrece el postmodernismo artístico. Por lo cual podemos decir con G. Zalamea "echando mano de toda la tradición, la más alejada y la más reciente, la culta y la popular, los artistas hacen pedazos una visión lineal y unívoca, y están reivindicando la pluralidad, el mestizaje, la hibridación, sin renunciar por ello a la significación y la trascendencia" ${ }^{45}$.

43. ACHA, Juán. Op. Cit. P. 112.

44. GARCIA CANCLINI, Nestor. Op. Cit. P. 312-313.

45. ZALAMEA, Gustavo. Op. Cit.P. 4. 
Esbozadas todas las anteriores razones se puede afirmar que una vez sean comprendidas y asumidas las nociones de modernidad-postmodernidad; la conceptualización y caracterización del postmodernismo artístico; las fisuras y rupturas causadas al arte moderno; las implicaciones ideológicas y las justificaciones para refuncionalizar el postmodernismo; las respuestas dadas por el arte al declive de las certezas, la globalización económica-cultural y al yo ilimitado, como dimensiones fundantes de la postmodernidad; y los proceso educativos emergentes es bien posible desarrollar propuestas creativas que transformen y proyecten nuestras artes visuales.

Sin embargo tan importante es reconocer la anterior problemática artística como reflexionar sobre la manera como el arte actual puede contribuir a la modificación de nuestra cultura y con cuales proyectos se pueden cualificar las necesidades estéticas y artísticas de nuestra sociedad. Porque sólo una educación artística pertinente, el empleo de la educación por el arte; la reorientación de las políticas, planes y proyectos culturales; el uso de los medios masivos de comunicación para alfabetizar didácticamente la visualidad de la población; el reordenamiento de los circuitos de creación - valoración - difusión-consumo; y la reconstrucción de los espacios públicos y privados, podrán también modificar las concepciones que orientarán el quehacer de nuestras artes visuales de forma auténtica, independientemente de los códigos que emplean; pero esto será materia de otro ensayo.

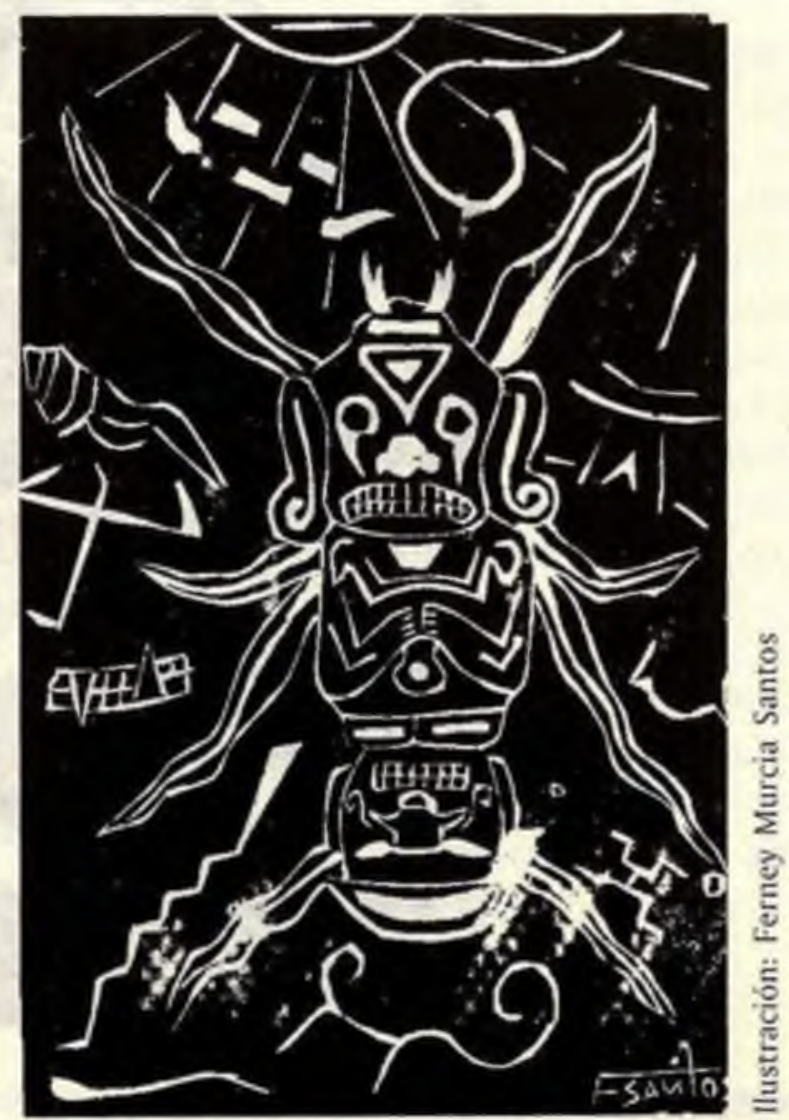




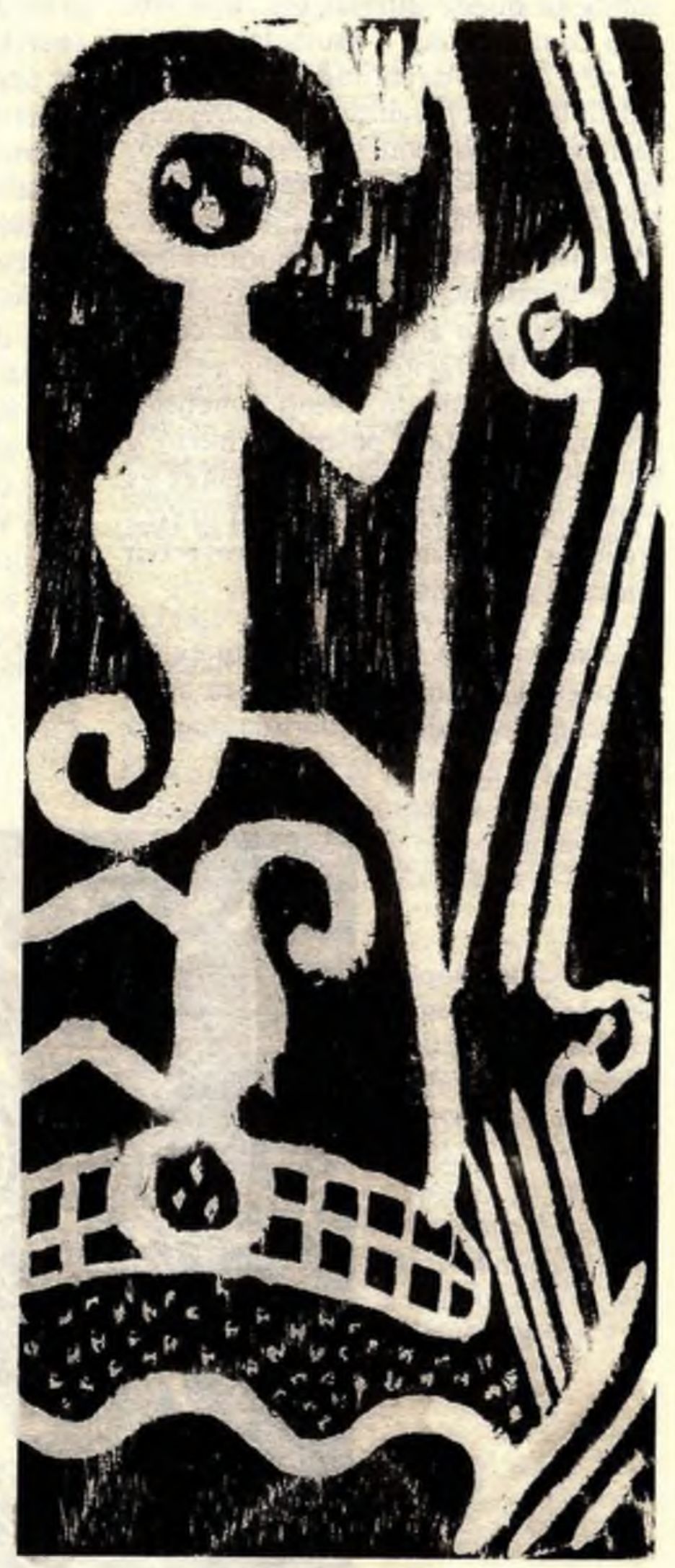

Ilustración: Alexander Salazar 